\section{MS30-02 Structure and function of coordination compounds for radiopharmaceutical application}

\author{
Andreas Roodt $^{1}$, Alice Brink ${ }^{1}$, Marietjie Schutte-Smith ${ }^{1}$, Hendrik \\ G. Visser ${ }^{1}$
}

1. Department of Chemistry, University of the Free State, Bloemfontein 9300, South Africa

email: roodta@ufs.ac.za

Many dynamic processes occur at the molecular level; thus fundamental understanding of structural behavior, and the associated influence on (kinetic) properties is still of prime importance. Herein we emphasize the continued relevance of small molecule crystallography in coordination chemistry in conjunction with an integrated mechanistic approach utilising spectroscopic techniques and specifically reaction kinetics, to counteract trivialized conclusions based on thermodynamic observations alone [1].

We highlight dynamics in small coordination compounds utilised as model radiopharmaceuticals and the importance of structure of the compounds on some functions thereof. The $4^{\text {th }}$ and $5^{\text {th }}$ row elements of the manganese triad, and in particular the ${ }^{99 \mathrm{~m}} \mathrm{Tc},{ }^{188} \mathrm{Re},{ }^{186} \mathrm{Re}$ isotopes, find widespread application in nuclear medicine $[2,3]$. Thus, the $\mathrm{fac}-\left[\mathrm{M}(\mathrm{CO})_{3}\right]^{+}$core $\left(\mathrm{M}={ }^{99 \mathrm{~m}} \mathrm{Tc},{ }^{99} \mathrm{Tc}\right.$, ${ }^{188} \mathrm{Re},{ }^{186} \mathrm{Re}$ ) is of continued interest due to its potential in biomedical applications since it is a low-valent, low-spin, kinetically inert organometallic core with high in vivo stability. It coordinates many types of ligands which determine the hydro- and lipophilic properties.

Many overarching aspects of radiopharmaceuticals are imperative for its successful application; in particular, those associated with and directly influencing the kinetic stability and/or reactivity, and can be quite diverse. It is therefore important to consider these aspects in an overarching approach to enable better understanding and consequent potential more accurate prediction of in vivo behavior thereof [1, 3-6].

This presentation will underline some of the above mentioned aspects on small coordination compounds, and illustrate the importance of structure and concurrent different processes/ factors which significantly influence the kinetics in metal complexes and the structures thereof, including radiopharmaceutical models.

[1] Roodt, A.; Visser, H.G. \& Brink, A. Crystallogr. Rev. 2011, 17, 241.

[2] Alberto, R.; Schibli, R.; Waibel, R.; Abram, U. \& Schubiger, A.P. Coord. Chem. Rev. 1999, 901.

[3] Schutte, M.; Kemp, G.; Visser, H.G. \& Roodt, A. Inorg. Chem. 2011, 50, 12486.

[4] Brink, A.; Visser, H.G. \& Roodt, A. Inorg. Chem. 2013, 52, 8950 .

[5] Brink, A.; Visser, H.G. \& Roodt, A. Inorg. Chem. 2014, 53, 12480.

[6] Twala, T.N.; Schutte-Smith, M.; Roodt, A. \& Visser, H. G. Dalton Trans. 2015, 44, 3278.

Keywords: Coordination compounds, kinetics, structures, radiopharmaceuticals, rhenium.

\section{MS30-O3 Guest-responsive metal-organic frameworks based on asymmetric bridging ligands \\ Susan A. Bourne ${ }^{1}$, Gift Mehlana ${ }^{1}$, Gaelle Ramon ${ }^{1}$}

1. Centre for Supramolecular Chemistry Research, Department of Chemistry, University of Cape Town, Rondebosch 7701, South Africa

email: susan.bourne@uct.ac.za

Polymeric coordination compounds, and their subset metal-organic frameworks (MOFs) have provided a rich source of interest to researchers in solid state functional materials [1]. The inherent porosity achievable for 2D and 3D network structures generated from bridging ligands coordinated to metal ions allows for applications as diverse as catalysis, gas storage, separation and extraction [2]. While interpenetration can sometimes appear as a hindrance to engineering highly porous materials, it may hold some advantages in terms of thermal stability and increased functionality. Examples from our recent work will be presented, including MOFs incorporating $\mathrm{Co}$ (II) and $\mathrm{Zn}(\mathrm{II})$ with flexible pyridylcarboxylate ligands. These MOFs are robust to solvent loss. New crystalline phases result from the exposure of the empty frameworks to various solvents (Figure 1). The resulting solvatochromism has been correlated to solvent properties [3, 4].

\section{References}

1. Recent reviews: (a) A. Phan, C. J. Doonan, F. J. Uribe-Romo, C. B. Knobler, M. O'Keeffe, O. M. Yaghi, Acc. Chem. Res., 2010, 43, 58. (b) C. Janiak, J. K. Vieth, New J. Chem., 2010, 34, 2366. (c) J. J. Perry, J. A. Perman, M. J. Zaworotko, Chem. Soc. Rev., 2009, 38, 1400 .

2. Recent examples include (a) O. K. Farha, Y. A. Oezguer, I. Eryazici, C. D. Malliakas, B. G. Hauser, M. C. Kanatzidis, S. T. Nguyen, R. Q. Snurr, J. T. Hupp, Nat. Chem., 2010, 2, 944. (b) S. Wang, J. Lin, X. Wang, Phys. Chem. Chem. Phys. 2014, 16, 14656.

3. G. Mehlana, G. Ramon, S. A. Bourne. CrystEngComm, 2013, 15, 9521.

4. G. Mehlana, G. Ramon, S. A. Bourne, CrystEngComm, 2014, 16, 8160.

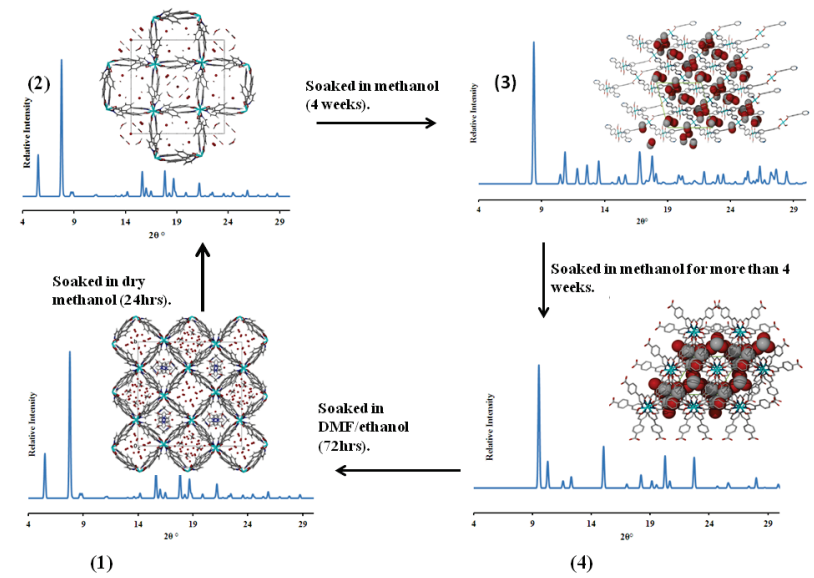

Figure 1. Phase transformations in a $\mathrm{Co}(\mathrm{II}) \mathrm{MOF}$.

Keywords: MOF, solvatochromism, thermochromism, 